\title{
Predispozan bir Aspergillus Olgusunda Postoperatif Gelișen Bronkoplevral Fistül: Radyolojik Değerlendirmesi
}

\author{
Postoperative Developing Bronchopleural Fistula in a Patient Having \\ A Predisposing Aspergillus: Radiological Evaluation
}

\author{
İshak YILDIZHAN (D), Bilgin Kadri ARIBAȘ (D) \\ Zonguldak Bülent Ecevit Üniversitesi, Tıp Fakültesi, Radyoloji Anabilim Dalı, Zonguldak, Türkiye \\ ORCID ID: İshak Yıldızhan 0000-0002-5707-548X, Bilgin Kadri Arıbaș 0000-0001-8218-1359
}

Bu makaleye yapılacak atıf: Yıldızhan i ve Arıbaș BK. Predispozan bir Aspergillus Olgusunda Postoperatif Gelișen Bronkoplevral Fistül: Radyolojik Değerlendirmesi. Med J West Black Sea. 2021;5(1):101-105.

Sorumlu Yazar

İshak Yıldızhan

E-posta

ishaky69@gmail.com

Geliș Tarihi

01.06.2020

Revizyon Tarihi

07.12.2020

Kabul Tarihi

10.12.2020
Öz

Bronkoplevral fistül (BPF), torasik cerrahi sonrası gelişebilecek en kötü komplikasyonlardan biridir. Bildirilen sıklığı \%0.8-15'tir ve mortalite oranı \%30-70 olup çoğunlukla sağ pnömonektomiden sonra görülür. Preoperatif kontrol edilemeyen plevropulmoner enfeksiyon, travma ve preoperatif radyoterapi uygulanması predispozan faktörlerdir. BPF'deki bilgisayarlı tomografi (BT) bulguları plevral alandaki hava-Sıvı koleksiyonunu içerir ve hava yolundan veya akciğer parankiminden plevral alana olan fistül yolu veya ilişkiyi gösterir. Bu olguda predispozan olarak sağ akciğerde tedaviye yanıt vermeyen aspergillus nedeniyle sağ lobektomi uygulanan ve operasyon sonrasında bronkoplevral fistül gelişen 65 yaşındaki kadın hastanın klinik ve radyolojik bulgularını sunuyoruz. Pnömonektomi veya lobektomi sonrasında diğer komplikasyonların değerlendirilmesi için klinik yakın takip önemlidir. Takipler sırasında radyolojik akut değişiklikler klinik olarak az öneme sahip olsalar bile diğer büyük problemlerin önemli habercisidir. Radyolojik takipler sırasında ufak değişiklikleri kapsamada girişimsel olmayan bilgisayarlı tomografi ilk tercih olmalıdır.

Anahtar Sözcükler: Bronkoplevral, Fistül, Bronşial, BT, Aspergillus, Lobektomi

\section{ABSTRACT}

Bronchopleural fistula (BPF) is one of the worst complications that can occur after thoracic surgery. The reported incidence is $0.8-15 \%$ and the mortality rate is $30-70 \%$, mostly seen after right pneumonectomy. Preoperative uncontrolled pleuropulmonary infection, trauma and preoperative radiotherapy are predisposing factors. Computed tomography (CT) findings in BPF include air-fluid collection in the pleural area and show the fistula tract or relationship from the airway or lung parenchyma to the pleural space. In this case, we present the clinical and radiological findings of a 65-year-old female patient who underwent right lobectomy due to aspergillus that did not respond to treatment in the right lung and developed a post-operative bronchopleural fistula. Close clinical follow-up is important to evaluate for other complications after pneumonectomy or lobectomy. Radiological acute changes during follow-up are important precursors of other major problems, even though they are of little clinical importance. Non-invasive CT should be the first choice in determining minor changes during radiological follow-up.

Keywords: Bronchopleural , Fistula, Bronchial, CT, Aspergillus, Lobectomy 


\section{GiRiş}

Bronkoplevral fistül (BPF), genellikle pnömonektomi veya diğer pulmoner rezeksiyonlar sonrasında gelişen katastrofik bir komplikasyonudur (1). Diğer genel nedenleri arasında enfeksiyon sonrası gelişen nekroz, persistan spontan pnömotoraks, malignite sebebiyle verilen kemoterapi ve radyoterapi ve tüberküloz sayılabilir. Bu komplikasyon sık görülmese de bildirilen sıklığı, \%0.8-15’tir $(2,3)$. Pnömonektomi sonrası \%4.5-20, lobektomi sonrası \%0.5-1'dir $(2,4,5)$.

Mortalite oranı çalışmalara göre farklılık gösterse de ortalama \%25-75'tir $(1,2,4,5)$. Bu da her şekilde mortalitenin yüksek olduğunu göstermektedir. Bronkoplevral fistül komplikasyonu erken (1-8 gün), orta (8-30 gün) ve geç komplikasyon olarak (>30 gün) olarak karşımıza çıkabilir (2). Postoperatif ilk iki haftada mortalite oranı en yüksektir (4). Bu nedenle tanı konulması ve belirlenmesi çok önemlidir. Öncelikle direkt grafi ile değerlendirilmesi ve saptanamaması durumunda da bilgisayarlı tomografi (BT) ile teyit edilmelidir (5). Ölümün en önemli sebebi eşlik eden aspirasyon pnömonisi ile tansiyon pnömotoraks veya erişkinin solunum zorluğu sendromudur $(1,4)$. BPF, pnömotoraksa benzemekle birlikte; farklı olarak, distal hava değişim ünitelerinden çok, proksimal hava yolları plevra ile ilişkilidir $(2,5)$.

$\mathrm{Bu}$ olgu sunumumuzda torasik cerrahi sonrası bronkoplevral fistül gelişen ve aynı zamanda predispozan aspergilloması mevcut olan hastanın klinik ve radyolojik bulgularını sunmayı ve literatür bilgileri ile tartışmayı amaçladık.

\section{OLGU}

Elli bir yaşında kadın hasta hemoptizi ve öksürüğü nedeniyle dış merkezden hastanemize aspergilloma tanısı ile başvurmuştur. Hasta ilk geldiğinde görüntülenme yapıldı ve iki adet aspergilloma ile uyumlu odak izlendi (Şekil 1). Bunun üzerine vorikonazol (5 mg/kg) başlandı.

Hastanın izlemi sırasında karaciğer fonksiyon testlerinin (KCFT) artması üzerine ilaca ara verildi. PET-BT çekilmesine karşın malignite ekartasyonu yapılamadı. Sağ akciğere tru-cut biyopsi yapılması sonrasında yoğun fungal mikroorganizma olduğu saptandı.

Antifungal tedaviye ara verildikten sonra semptomların tekrar nüks etmesi üzerine ilaç tekrar başlandı. İzlem sırasında KCFT artışı üzerine sağ alt lobektomi yapıldı. Takip akciğer grafilerinde hava ve sıvı olmaması üzerine serbest su altı tüp drenajı çıkarıldı (Şekil 2). Hastaya direkt grafi izlemi yapıldı (Şekil 3). İzlem sırasında pnömotoraks ve sıvı seviyesinde artış olması üzerine BT çekildi (Şekil 4).

Tekrar operasyon planlanıp fistül traktı kapatılıp izleminde komplikasyon gelişmemesi üzerine hasta taburcu edildi.
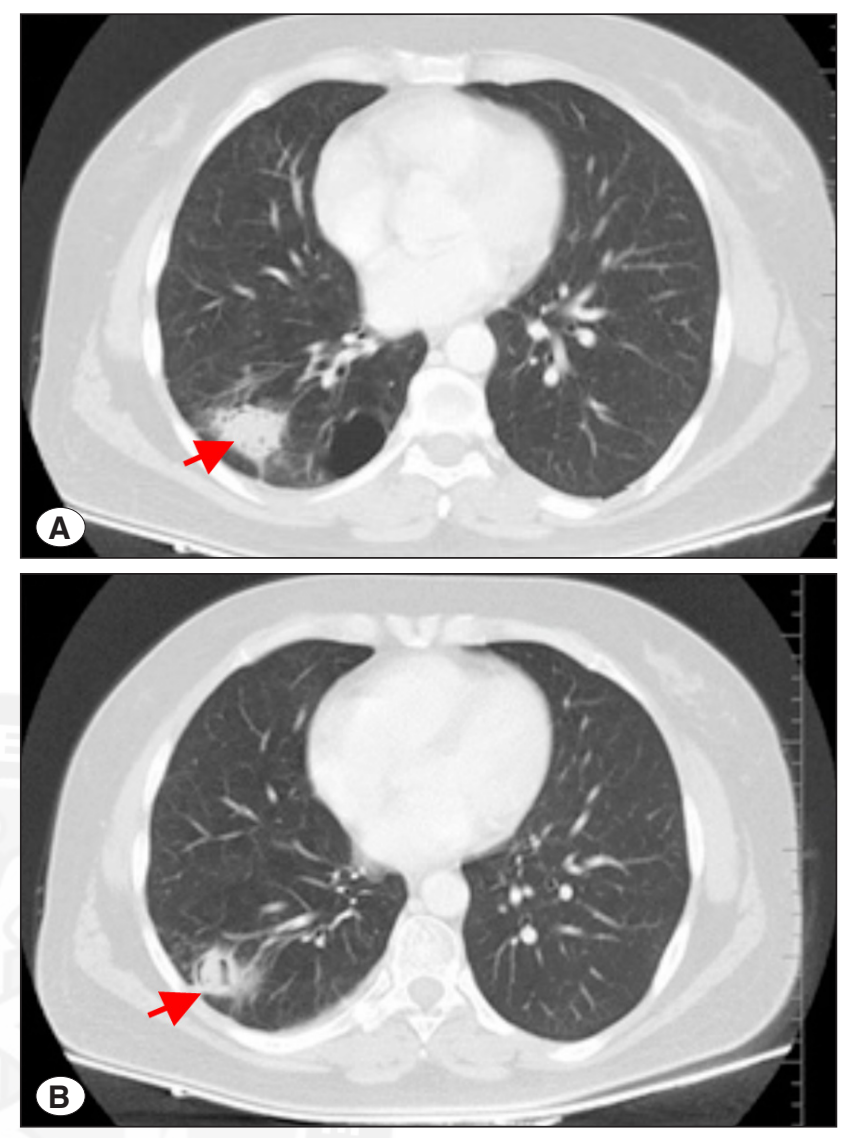

Şekil 1: Hastanın başvurusu sırasında çekilen kontrastlı toraks BT'sinde sağ akciğer alt lobda tipik iki farklı odakta aspergilloma ile uyumlu serbest fungus topu ve medialinde eşlik eden bül (A) ve 'air-crescent' bulgusu olan diğer nodüler dansite (B) görülmektedir.

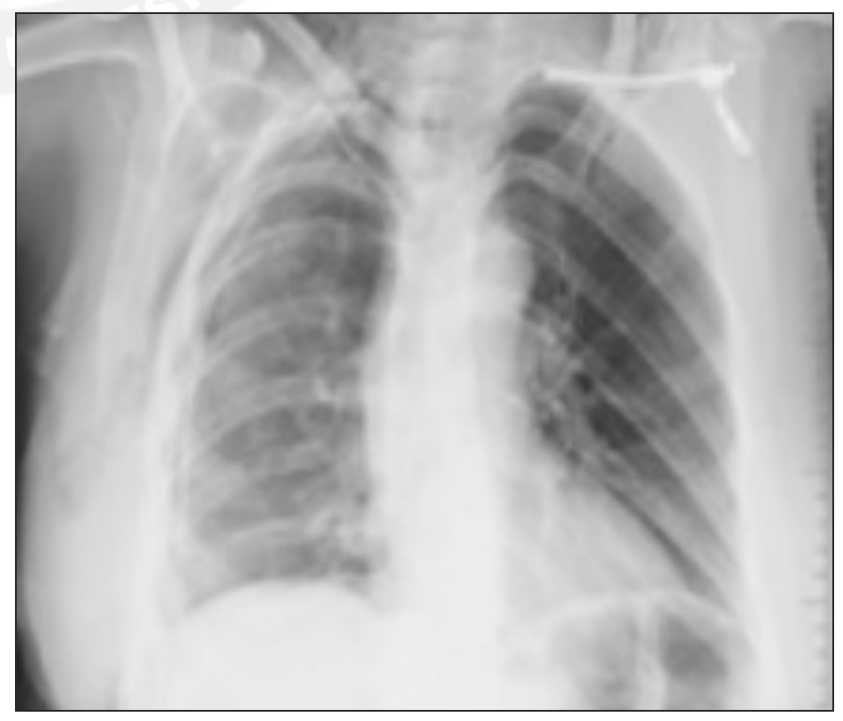

Şekil 2: 10.11.2017'de hastanın pnömotoraksı ve sıvı seviyesi regrese olması üzerine tüp çekilmeden önce PA akciğer grafisi. 

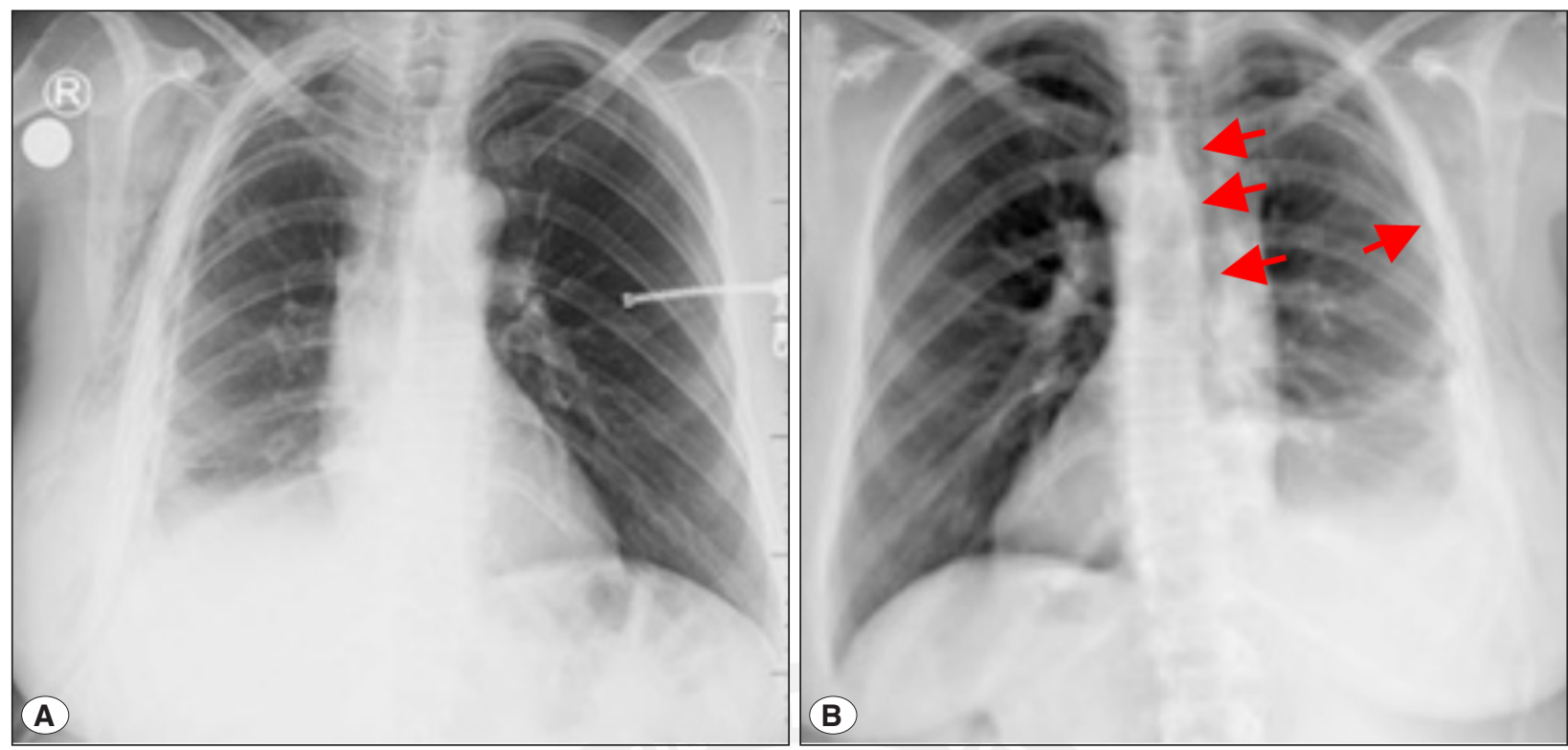

Şekil 3: Serbest su altı drenajının çekilmesinden sonraki ilk akciğer filminde sağda hafif düzeyde pnömotoraks, sağ kostofrenik sinüste silinme diyafragmada yükselme izleniyor (A). Kontrol akciğer grafisinde hava-sıvı seviyesi ve pnömotoraskta artış (B)
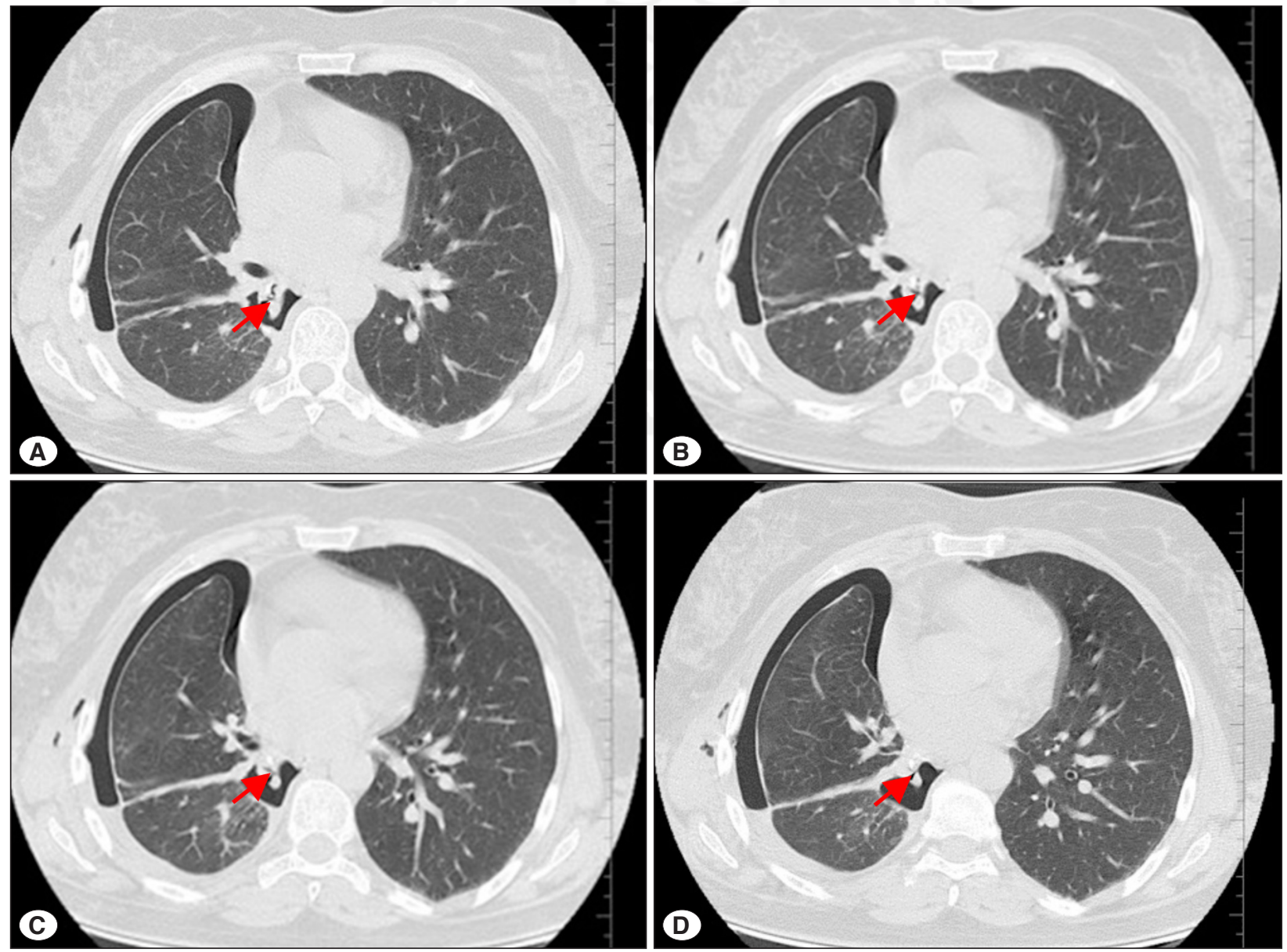

Şekil 4: A-D) Pnömotoraks artışı üzerine çekilen kontrastlı bilgisayarlı tomografi (BT)'de alınan ardışık kesitlerde siyah ok (A-D) ile fistül traktı gösterilmektedir. 


\section{TARTIŞMA}

Pulmoner rezeksiyon sonrasında erken dönemde en sık gözlenen komplikasyonlar arasında pulmoner ödem, BPF, aspirasyon pnömonisi, ampiyem, kontralateral akciğerde pnömoni yer alır (2-5). Postoperatif komplikasyonlar arasında yer alan BPF ise, daha çok sağ pnömonektomiden sonra görülür (1,4-6). Bunun muhtemel nedeni, sağ ana bronşun anatomik yapısı ile ilgilidir. Sağ ana bronş sol ana bronşa göre daha geniş çaplıdır, daha esnektir ve daha az plevra ile kaplıdır (2). Bu nedenle tanı konulması ve belirlenmesi çok önemlidir.

BPF akciğer parankiminden veya bronşial güdükten gelişir $(1,2)$. Postoperatif erken dönemde, bronşial sızıntı nadir olmakla birlikte güdük uzunluğunun artması BPF için predispozan faktördür. Genellikle bronşların hatalı kapatılmasından kaynaklanır. Postoperatif mekanik ventilasyon uygulanmasına bağlı olarak da BPF gelişebilir $(2,4,5)$.

Preoperatif kontrol edilemeyen plevropulmoner enfeksiyon, travma ve preoperatif radyoterapi uygulanması da predispozan faktörlerdir $(4,5)$. Olgumuzda da preoperatif kontrol edilemeyen aspergillus enfeksiyonunun, postoperatif BPF oluşumunda predispozan bir faktör olarak rol oynadığı görülmüştür. Bu nedenle preoperatif kontrol edilemeyen aspergillus enfeksiyonu gibi olgularda hastanın postoperatif yakın takibi sağlanmalıdır.

Postoperatif gelişen ateş, hemoptizi, prodüktif öksürük ve plevral drende devam eden bol miktarda havanın varlığı durumunda BPF'den şüphelenilmelidir $(1,2)$. Hastamızın klinik seyrinde bozulma erken bir komplikasyon olduğu lehine değerlendirildi.

Pulmoner rezeksiyon sonrasında gelişen çeşitli komplikasyonların tanısında radyolog önemli rol oynar. BPF'nin radyolojik bulguları şunlardır $(1,2,5)$ : a) Rezidüel intraplevral hava alanında sürekli artış, b) Hava-sıvı seviyesi görülmesi, c) Mevcut hava-sıvı seviyesindeki değişiklik, d) Tansiyon pnömotoraks gelişmesi, e) Mediastenin preoperatif pozisyonuna geri dönmesi, f) Ara sıra gelişen aspirasyon pnömonisi. g) Direkt fistül yolunu gösterilmesi. Olgumuzda a, b, c ve $g$ maddelerindeki bulgular saptanmıştır.

Ameliyat sonrası erken dönemde özellikle göğüs grafileri ve ardışık muayeneler pnömonektomi sonrası gelişen komplikasyonları saptamada değerlidir. Bazen BPF'de, rezidüel aralık plevral fibrozis ve skar dokusuyla çevrelendiğinden, takip grafilerde hava alanlarında değişiklik görülmeyebilir. $\mathrm{Bu}$ durumda, direkt grafideki BPF işaretlerinden "plevral hava artışı" görülmez. Aynı zamanda, yoğun skar gelişimi, mediastinal şifti de engelleyebilir. Bu durumda BT görüntüleme olgumuzda olduğu gibi daha net ve fazla bilgi verdiği için önerilmektedir.
Bronkoplevral fistülün tanısında BT yararlı bir yöntemdir. BT, plevral alandaki hava-sıvı koleksiyonunu ve hava yolundan veya akciğer parankiminden plevral alana olan fistül yolunu gösterir $(4,5,6)$. Tsubakimoto ve ark.nın yaptığı bir çalışmaya göre ince kesit BT'de bronokoplevral fistül yolunu gösterilmesi \%50-76 arasında yapılmıştır (7). Olgumuzun BT'sinde sağ hemitoraksta, plevral mesafede serbest hava ve bazalde septal kalınlık artışı ile sıvı lokülasyonu olup fistül yolu izlendi. BT ile fistül yolu gösterilemeyen durumlarda ise klinik bulgular ile korelasyon, bronkoskopi, tüp torakostomi eşliğinde endobronşial metilen mavisi verilmesi veya SPECT ile ventilasyon görüntüleme yapılarak tanı konabilir (8).

Tedavisi için kullanılan yöntemlerden bir diğeri bronkoskopik embolizasyondur. Akciğer fonksiyon kapasitesi düşük hastalarda embolizasyonun dikkatlice yapılması önemlidir. Embolizasyon yapılmadan önce işaretleme yapılmıştır. BT ile de teyit edilmesi önemlidir.

Predispozan aspergillus gibi kontrol edilemeyen enfeksiyonu olan lobektomili hastalarda plevral mesafede hava ya da devam eden hava-sıvı koleksiyonu bronkoplevral fistülü düşündürmelidir. İnvaziv olmayan bir yöntem olarak, bronkoplevral fistül yolu net olarak gösterebildiği için ince kesit BT'nin çekilmesi gereklidir.

\section{Teşekkür}

Yazarlar, COVID-19 pandemi sürecinde üstün gayretleri ile görevini yerine getiren tüm Zonguldak Bülent Ecevit Üniversitesi Sağlık Uygulama ve Araştırma Merkezi-Hastanesi çalışanlarına teşekkür ederler.

Ayrıca olgu ile ilgili Göğüs cerrahisi uzmanı Dr.Aykut Eliçora'ya teşekkür ederiz.

\section{Yazar Katkı Beyanı}

Fikir: İshak Yıldızhan, Tasarım: İshak Yıldızhan, Bilgin Kadri Arıbaş Denetleme: Bilgin Kadri Arıbaş, Kaynak ve Fon Sağlama: İshak Yıldızhan, Bilgin Kadri Arıbaş, Veri Toplama ve/ veya İşleme: İshak Yıldızhan, Bilgin Kadri Arıbaş Analiz -Yorum: İshak Yıldızhan, Bilgin Kadri Arıbaş, Literatür Taraması: İshak Yıldızhan, Makale Yazımı: İshak Yıldızhan, Bilgin Kadri Arıbaş, Eleştirel İnceleme: Bilgin Kadri Arıbaş

\section{Çıkar Çatışması}

Yazarların bir çıkar çatışması bulunmamaktadır.

\section{Finansal Destek}

Olgu sunumumuz ile iliş̧ili olarak finansal destek alınmamıştır

\section{Etik Kurul ve Hasta Onamı}

Olgu sunumu olduğundan etik kurul oluru gerekmemiştir. Hastaya ait gerekli onam alınmıştır. 


\section{Hakemlik Süreci}

Kör hakemlik süreci yayınlanmaya uygun bulunmuş ve kabul edilmiştir.

\section{KAYNAKLAR}

1. Arrivé L, Tasu JP, Kitzis M, Lesêche G, Najmark D, Duchatelle $\mathrm{JP}$, Nahum $\mathrm{H}$. Open window thoracostomy, myoplasty, and epiploplasty for treatment of postpneumonectomy empyema: CT evaluation. Radiology 1994;192(1):177-181.

2. Salik I, Abramowicz AE. Bronchopleural Fistula. [Updated 2019 Oct 28]. In: StatPearls [Internet]. Treasure Island (FL): StatPearls Publishing; 2020 Jan-. Available from: https:// www.ncbi.nlm.nih.gov/books/NBK534765/ Copyright (c) 2020, StatPearls Publishing LLC. http://creativecommons.org/ licenses/by/4.0/, Bookshelf ID: NBK534765

3. Mueller DK, Whitten PE, Tillis WP, Bond LM, Munns JR. Delayed closure of persistent postpneumonectomy bronchopleural fistula. Chest 2002;121(5):1703-1704.
4. Sarkar $P$, Chandak $T$, Shah R, Talwar A. Diagnosis and management bronchopleural fistula. Indian J Chest Dis Allied Sci 2010;52:97-104

5. Chae EJ, Seo JB, Kim SY, Do KH, Heo JN, Lee JS, Song KS, Song JW, Lim TH, Radiographic and CT findings of thoracic complications after pneumonectomy. Radiographics 2006; 6(5):1449-1468.

6. Zhang C, Pan Y, Zhang RM, Wu WB, Liu D, Zhang M. Lateonset bronchopleural fistula after lobectomy and adjuvant chemotherapy for lung cancer: A case report and review of the literature. Medicine (Baltimore) 2019;98(26):e16228.

7. Tsubakimoto $M$, Murayama $S$, Iraha $R$, Kamiya $H$, Tsuchiya $\mathrm{N}$, Yamashiro T. Can peripheral bronchopleural fistula demonstrated on computed tomography be treated conservatively? A retrospective analysis. J Comput Assist Tomogr 2016;40(1):86-90.

8. Fuso L, Varone F, Nachira D, Leli I, Salimbene I, Congedo MT, Margaritora S, Granone P. Incidence and management of postlobectomy and pneumonectomy bronchopleural fistula. Lung 2016;194: 299-305. 